\title{
Oryzias melastigma - an effective substitute for exotic larvicidal fishes: enhancement of its reproductive potential by supplementary feeding
}

\author{
Abir Lal Dutta ${ }^{1 *}$, Sajal Kumar Dey ${ }^{1}$, Debargha Chakraborty ${ }^{2}$, Asim Kumar Manna ${ }^{3}$ and Pankaj Kumar Manna ${ }^{4}$
}

\begin{abstract}
A preliminary study was conducted on the efficacy of Oryzias melastigma in consuming mosquito larva so as to control mosquito and mosquito borne diseases, and enhancing its reproductive success using supplementary feed. Oryzias melastigma is a larvivore fish and widely distributed in the shallow water, wetlands of Gangetic plains and peninsular India. These studies indicate that O. melastigma is a prolific breeder and gregarious feeder of mosquito larvae. Increased reproduction by providing different supplementary feed, of which Ulothrix acted remarkably, may aid in wide spread use of this fish as a biological control measure against mosquitoes. One adult fish of any sex can consume $87.1 \%$ first instars mosquito larvae/day. So, early stages of mosquito larvae are effectively controlled, as compared to other successive stages. Ulothrix has considerable effect on egg production, successful hatching and regaining reproductive maturity of female in surprisingly quicker interval.
\end{abstract}

Keyword: Oryzias melastigma, Ulothrix, Larvicidal fish, Biological control, Indigenous, Reproductive potential

\section{Background}

Mosquito borne diseases are a major problem in all tropical and subtropical countries and are responsible for causing some of the most life threatening diseases in man, like malaria, dengue fever, filariasis, encephalitis and chikungunya. The harmful effects caused by chemicals, for instance DDT, in mosquito as well as on non target populations and the development of resistances in mosquitoes have prompted an alternative use of simple and sustainable methods of mosquito control (Milam et al. 2000).

Larvivorous fishes are being successfully exploited for mosquito control in various countries like Spain, Italy, Greece, Southern Europe, Northern Africa, India, Iran, Malaysia, Madagascar and many other countries (Bruce-Chwatt 1985). They are either employed for the destruction of larvae or to render the habitat unsuitable for mosquito to breed.

Larvivorous fishes are those that feed on immature stages of mosquitoes. They are mostly small, hardy and

\footnotetext{
* Correspondence: abirlaldutta1@gmail.com

${ }^{1}$ Department of Zoology, University of Kalyani, Nadia, Kalyani, West Bengal, India

Full list of author information is available at the end of the article
}

capable of maneuvering easily in shallow waters where mosquitoes breed. They must be drought resistant and capable of flourishing in both deep and shallow waters. They must have the ability to withstand rough handling and transportation over long distances. These fishes must be prolific breeders with a shorter span of life with having the ability to breed successfully in confined waters. They should be surface feeders, carnivores in habit and should have a predisposition to feed on mosquito larva even in the presence of other food materials. Among important criterion for all larvivorous species is that they should not be brightly coloured or attractive. Besides, they should be unpalatable with no food value so that they are discarded by fish-eating people (Job 1940).

O. melastigma (McClelland 1839) belonging to the Order Beloniformes, Family Adrianichthyidae and Subfamily Oryzinae (Jayaram 1981), is a tiny cyprinodontid weed fish. It is a carnivorous, surface feeder found in both lentic and lotic waters. It is a semitransparent and hardy fish which can tolerate a wide range of salinity (31ppm) (Manna 1989), temperature, and many other adverse water qualities. Popularly known as rice fish or minnow (Rosen and Parenti 1981) or Indian Medaka or Bechi, it is a sexually dimorphic species (Manna and 
Bannerjee 1984). It is found in limited areas of West Bengal, Tamil Nadu, Kerala, Orissa (Jayaram 1981; Manna and Bannerjee 1985) in India and also some riverine areas of Bangladash. In West Bengal, they are mainly distributed in the lower Gangetic shallow water bodies of 24 pargans, Midnapore and Howrah district. They generally lay eggs two to four times in a year and show a notable parental care and their breeding rate is higher as compared to other minnows under certain conditions (Daniels and Ranjit 2002). This experiment has been designed to study the increase in reproductive success of $O$. melastigma by giving different supplementary feeds and to study its potentiality in mosquito control.

\section{Methods}

In the present experiment $O$. melastigma were collected from fresh water pond of Midnapore and maintained in a cement cistern (20 liters), where they could breed successfully. The eggs were collected time to time, hatched in laboratory condition and reared in separate glass aquaria $(55.88 \mathrm{~cm} \times 30.48 \mathrm{~cm} \times 30.48 \mathrm{~cm})$, each filled with 20 liter of tap water (1/4th of aquarium). The hatchlings were fed with natural feed till maturity. Six months old, healthy, disease-free specimens of both sexes of first filial generation were used for the present study.

Five males and five females of above specifications were released in experimental aquaria. Five such replicas were used for each of the first to third instars larvae and for pupae. Two earthen vats were maintained for stocking of mosquito larvae collected from drains and ditches. Sieves of specific mesh sizes were used to separate the larval insters of mosquitoes. After one hour of fish release, 100 larvae of desired instars were introduced each time in each experimental aquarium at 2 hourly intervals (6 times a day) and were observed till the end of tenure of the schedule. Suction pipettes were calibrated to count different larval instars in specific numbers for introduction in each aquarium each time. The fishes were fed and observed for 12 hours daily, for 20 consecutive days and the numbers of larvae consumed were noted and the specimens left were counted and removed. During rest of the observation period (12 hours) no food was supplied to keep them for food appetite. Reasonably sufficient numbers of larvae were supplied each time to minimize their energy expenditure for food search and to increase energy budget for feeding of minnows. However, preference of different species of mosquito larvae by the juveniles and sub-adults of the $O$. melastigma was not tried.

In a separate experimental set up, five pairs of adult $O$. melastigma (6 month old) were kept in each of the six aquaria where they were provided with different kinds of food supplement such as rice, semolina (suji), Ulothrix, and combinations of rice and Ulothrix, semolina and Ulothrix, and, semolina, rice and Ulothrix. Another set of five pairs of adult fishes were fed with natural food and was used as control. Water parameters were maintained; temperature from $26^{\circ} \mathrm{C}$ to $31^{\circ} \mathrm{C}$, pH from 6.34 to 6.61 and dissolved oxygen content from 5.28 to $6.47 \mathrm{mg} / \mathrm{ml}$. The behavioral patterns up to three generations were critically studied.

After each successful fertilization, from each of the aquaria, egg clutches were removed carefully with the help of a blunt forceps. Clutch size was measured and transferred to separate aquaria. Viability of the eggs was calculated in terms of fertilization success and hatching success. Hatchlings were reared to maturity to calculate the sex ratio of the new born. The design of present work is summerised schematically in Figure 1.

Data was statistically analysed using t-test. The maximum significant level chosen was $p<0.05$.

\section{Results and discussion}

Results based on multiple observations from 1st experimental set up demonstrate that adult $O$. melastigma feed successfully and vigorously on the early larval stages of mosquito. The first instars larvae were observed to be consumed at an average above 50 numbers/day/fish. The consumption rate decreased successively towards the advanced stages of mosquito and reached below 10 numbers/day/fish for the pupae. The percent consumption of 1st, 2nd and 3rd insters and pupae by each fish/day are presented in Figure 2. Results obtained from the 2nd experimental set-up show different reproductive efficiencies in fishes provided with different supplementary feed. Fishes fed with Ulothrix show a marked increment in egg production, fertilization success and hatchling survival as compared to other groups, including control. While each control female produces $44.667 \pm 1.196$ eggs, female fed with rice and suji produces $45.25 \pm 1.538$ and $45.083 \pm 1.554$ respectively, the Ulothrix-fed female produces $67.083 \pm 1.311$ eggs per laying. When Ulothrix was fed in combinations with rice, suji and rice-suji mixture, the clutch size per female was observed to be $48.833 \pm 1.036, \quad 50.167 \pm 1.120$ and $50.083 \pm 0.996$ respectively. Ulothrix, whether fed singly or in combinations, shows reasonably significant improvement in clutch size produced per female.

When percentage of fertilized eggs from the clutches was calculated, it was observed that $60.583 \%$ of control eggs, $64.167 \%$ eggs of rice fed group, $62.917 \%$ eggs of suji fed group, $78.167 \%$ eggs of Ulothrix fed group, 67.333\% eggs of rice + Ulothrix fed group, $67.583 \%$ eggs of suji + Ulothrix fed group and $71 \%$ eggs of suji + rice + Ulothrix fed group were fertilized. Hatching success, calculated as percentage of fertilized eggs hatched, shows highest viability of eggs of Ulothrix fed group. 95.833\% 


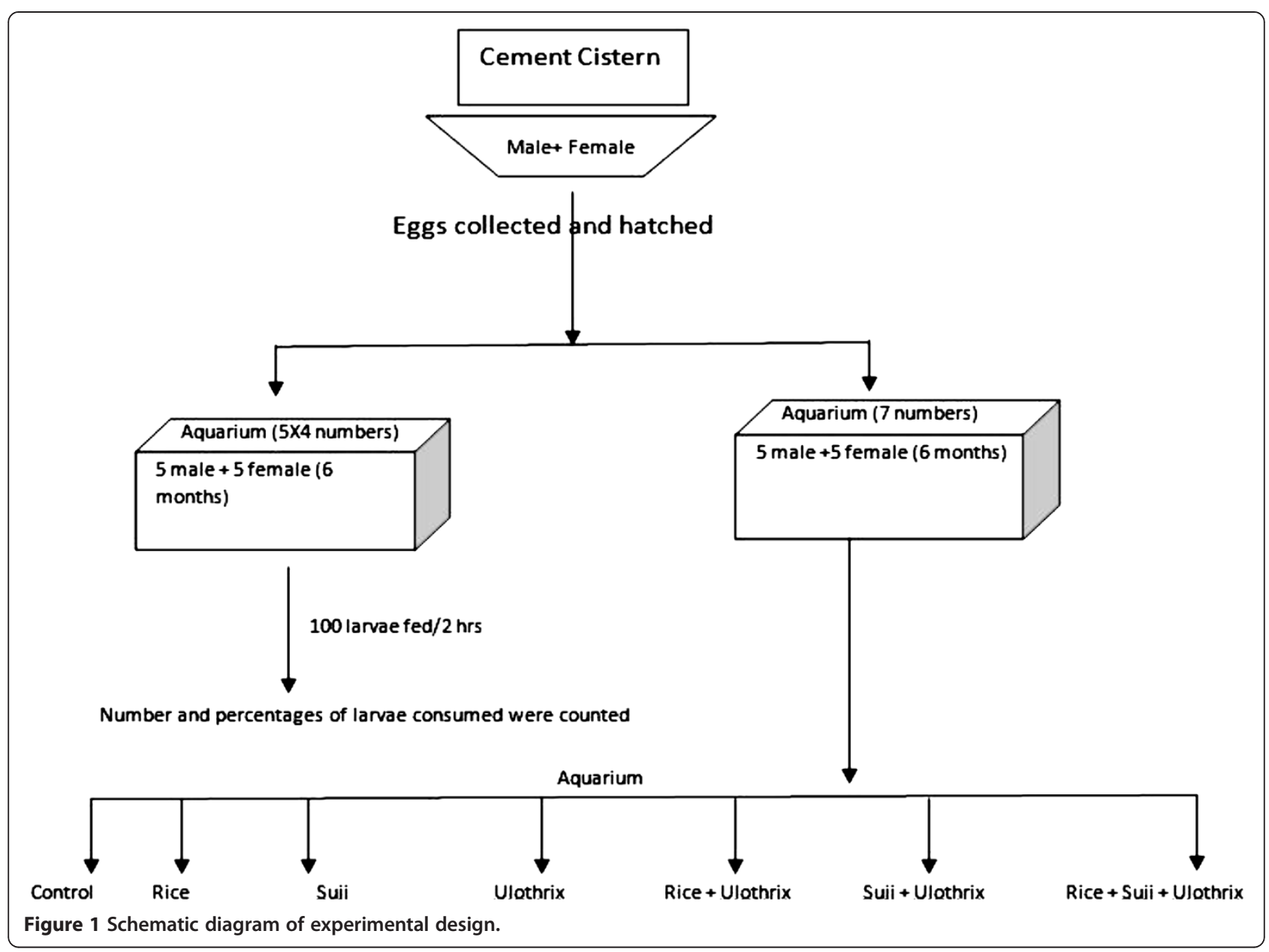

of fertilized eggs hatched successfully in this group. $80.583 \%, 84.083 \%$ and $86.75 \%$ of fertilized eggs in control, rice fed and suji fed groups were observed to be hatched respectively. Ulothrix along with rice or suji or rice + suji resulted in $85.413 \%, 84.75 \%$ and $87.25 \%$ hatching success respectively. Ulothrix has shown significant increase in producing fertilized eggs, whether fed singly or in combinations. However, combinations have no significant effect in increasing hatching success (Table 1).

Female:male ratio was observed above 1 in both the control and Ulothrix fed groups. The value was calculated as 1.07 in control which significantly increased to 1.33 in Ulothrix fed group. Removal of egg clutches from female enhances the reproductive maturity effectively.

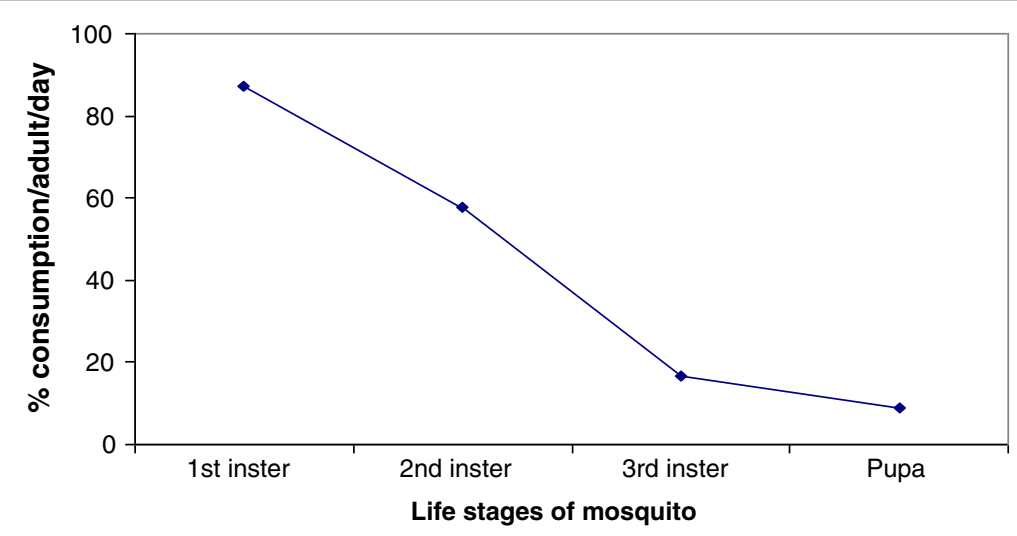

Figure 2 Percent consumption of different larval stages by 0 . melastigma. 
Table 1 Results of supplemented feeding on reproductive efficiency of 0 . melastigma

\begin{tabular}{llllllll}
\hline & $\mathrm{C}$ & $\mathrm{R}$ & $\mathrm{S}$ & $\mathrm{U}$ & $\mathrm{R}+\mathrm{U}$ & $\mathrm{S}+\mathrm{U}$ & $\mathrm{R}+\mathrm{S}+\mathrm{U}$ \\
\hline Clutch size & $44.667 \pm 1.196$ & $45.25 \pm 1.538$ & $45.083 \pm 1.554$ & $67.083 \pm 1.311^{* *}$ & $48.833 \pm 1.036^{*}$ & $50.167 \pm 1.120^{* *}$ & $50.083 \pm 0.996^{* *}$ \\
$\begin{array}{l}\text { Fertilized } \\
\text { eggs (\%) }\end{array}$ & $60.583 \pm 1.593$ & $64.167 \pm 1.604$ & $62.917 \pm 1.721$ & $78.167 \pm 2.584^{* * *}$ & $67.333 \pm 2.426^{*}$ & $67.583 \pm 2.454^{*}$ & $71 \pm 1.871^{* * *}$ \\
$\begin{array}{l}\text { Hatching } \\
\text { success (\%) }\end{array}$ & $80.583 \pm 1.823$ & $84.083 \pm 1.721$ & $86.75 \pm 1.733^{*}$ & $95.833 \pm 0.796^{* * *}$ & $85.413 \pm 1.900$ & $84.75 \pm 1.883$ & $87.25 \pm 1.706^{*}$ \\
\hline $\begin{array}{l}\text { All data are presented as mean } \pm \text { SEM from 12 similar experiments. Data } \\
\text { Al }\end{array}$ & & & & & \\
\hline
\end{tabular}

All data are presented as mean \pm SEM from 12 similar experiments. Data are significant at the level ${ }^{* *} p<0.001,{ }^{* *} p<0.01,{ }^{*} p<0.05$.

Adult females spawn biannually in the wild while the removal of eggs causes them to produce eggs 4 times a year in all the experimental groups except the Ulothrix fed group where it is found to increase phenomenally to 4 times a month i.e. 48 times a year. The higher ratio of female offspring and shortening of gestation period in Ulothrix fed group caused a dramatic rise in per annum production by a single pair of O. melastigma. It was calculated that a pair of control fish and their successive generations may cause a total production of about $4 \mathrm{Kg}$ per year whereas an Ulothrix fed pair and their forerunners would add up to a quintal per year.

Mosquitoes, potent vector of various life threatening diseases, are and will be the major concerns for human health. To find an effective solution for their control in the wild calls for introduction of efficient larvivorous fishes which prey on them in their natural habitat. A variety of larvivore fishes were tried and established as biological control measure against mosquitoes, of which most are exotic to Indian water bodies. For instance Gambusia affinis and Poecilia (Lebistes) reticulate have been extensively used in India for mosquito control. Though they have been found to be efficient in mosquito control, their adverse impact on local biodiversity must draw some attention of the ecologists. It has been reported that where Gambusia was introduced, often for mosquito control, has resulted in or has contributed to the exclusion of many native fishes which have similar ecological requirements (Page and Burr 1991). From a conservational view point, to protect the habitat of native species, World Health Organization has emphasized on research and introduction of indigenous fish species for mosquito control. The subject of present study, Oryzias melastigma, is a native species to Indian subcontinent distributed widely in many states of India and Bangladesh and is a hardy fish capable of propagating in shallow natural water bodies which happen to be the breeding ground of mosquitoes. From the present study it has been found that this fish has reasonably high feeding activity on mosquito larvae, especially on the early stages of mosquito life cycle. The efficiency of consumption gradually decreases as the life stages of mosquito progresses. This may be due to that the mouth of fish appears to be non-accommodative to engulf smoothly the larger larvae. Besides, as the larva develops, they sense the water movement more and learn to move away from the predator faster. It is also expected that the wriggling movement of the larvae is more attractive than the comparatively stationary late larvae and pupae.

The vigorous larvivore activity of this fish, as advocated in the present study, may suggest promote the rearing and breeding of $O$. melastigma for the control of mosquitoes. It also can be suggested that this fish is an efficient native alternative to the exotic vector control agents like Gambusia affinis and Poecilia (Lebistes) reticulate, as far as the larvae feeding ability is concerned (Chatterjee and Chandra 1997a, b).

Breeding of $O$. melastigma in captive condition has shown encouraging results with supplementary feed. It is found that the fish can be readily cultivated under laboratory conditions with different feed supplement exhibiting varying degrees of reproductive success. Ulothrix was observed to be most promising in enhancing the egg production, fertilization success and egg viability when supplemented singly or in combinations. Ulothrix must have some inducing effect on gonadal activity of both male and female fishes which need to be studied further. Results show that female to male ratio of produced offspring is on higher side in Ulothrix-fed pairs as compared to that of control pairs. Furthermore, removal of egg clutches from the female fed with Ulothrix resulted in an enhanced reproductive maturity leading to a remarkably high egg producing ability. All these reproduction enhancements aid in huge production of $O$. melastigma seeds that can be successfully released in the mosquito breeding grounds like drains/canals, septic tanks, cement tanks, pools/ponds, pit latrines, marshy lands, wells, overhead tanks, water meter chambers and miscellaneous household in domestic containers, for controlling mosquito menace.

\section{Conclusion}

The present study strongly advocates the larvivore efficacy of O. melastigma and potency as biological control measure against mosquitoes. This fish is an Indigenous alternative to exotic larvivores. It can be recommended that breeding this fish in captive condition using Ulothrix as a feed supplement can meet the need of an effective larvivorous fish for mosquito control. 


\section{Competing interests}

The authors declare that they have no competing interests.

\section{Authors' contribution}

ALD carried out the experiment and drafted the manuscript; SKD drafted the manuscript and contributed to statistical inferences; DC contributed towards finalizing the manuscript; AKM supervised the execution of the experiments; PK M hypothesised the experiment. All authors read and approved the final manuscript.

\section{Acknowledgement}

The authors sincerely acknowledge the teachers of Khejuri College for their constant support in performing this task successfully. The governing members of Academy of Biodiversity Conservation are also acknowledged for their guidance and enthusiasm. The authors are also thankful to the local people of Khejuri for their support.

\section{Author details}

${ }^{1}$ Department of Zoology, University of Kalyani, Nadia, Kalyani, West Bengal, India. ${ }^{2}$ Department of Environmental Science, University of Kalyani, Nadia, Kalyani, West Bengal, India. ${ }^{3}$ Khejuri College, Vidyasagar University, East Midnapore, West Bengal, India. ${ }^{4}$ Academy of Biodiversity Conservation, 97, Bangur Aveneue, Calcutta, West Bengal, India.

Received: 25 January 2013 Accepted: 30 April 2013

Published: 24 May 2013

\section{References}

Bruce-Chwatt $\sqcup$ (1985) Malaria, the growing medical and health problem. Drugs Exp Clin Res 11(12):899-909

Chatterjee SN, Chandra G (1997a) Feeding pattern on Gambusia affinis and Lebistes reticulates on Anopheles subpictus larvae in the laboratory and field condition. J Appl Zool Res 8:152-153

Chatterjee SN, Chandra G (1997b) Laboratory trials on the feeding pattern of Anopheles subpictus, Culex quinquefasciatus and Armigeres subalbatus larvae by Gambusia affinis. Seri Sci Cult 63:51-52

Daniels R, Ranjit J (2002) Freshwater fishes of peninsular India. Universities Press (India). Pvt Ltd, Hyderabad, India

Jayaram KC (1981) The freshwater fishes of India, Pakistan, Bangladesh, Burma and Sri Lanka. ZSI, Calcutta, India

Job TJ (1940) An investigation of the nutrition of the perches of the Madras coast. Rec Mind Mus 42:289-364

Manna AK (1989) Behavioral study of the weed fish Oryzias melastigma (McClelland). Environ Ecol 7:502-503

Manna AK, Bannerjee S (1984) Sexual dimorphism in the cyprinodontid weed fish Oryzias melastigma (McClelland). Sci Cult 50:329

Manna AK, Bannerjee S (1985) Breeding behavior and parental care of the fish Oryzias melastigma. Environ Ecol 3:456-457

McClelland (1839) http://www.marinespecies.org/aphia.php?p = taxdetails\&id = 315132

Milam CD, Farris JL, Wilhide J (2000) Evaluating mosquito control pesticide for effect on target and non-target organisms. Arch Environ Contam Toxicol 39:324-328

Page LM, Burr BM (1991) A field guide to freshwater fishes: North America North of Mexico (The Peterson Field Guide Series). Houghton-Mifflin Co., Boston, MA, pp 235-237

Rosen DE, Parenti LR (1981) Relationships of Oryzias and the groups of atherinomorph fishes. Am Mus Novit 27:1-2

doi:10.1186/2193-1801-2-235

Cite this article as: Dutta et al:: Oryzias melastigma - an effective substitute for exotic larvicidal fishes: enhancement of its reproductive potential by supplementary feeding. SpringerPlus 2013 2:235. 